\title{
The extrusion-capture model for chromosome partitioning in bacteria
}

\author{
Katherine P. Lemon ${ }^{1}$ and Alan D. Grossman ${ }^{2,3}$ \\ ${ }^{1}$ Harvard Medical School, Boston, Massachusetts 02115, USA; ${ }^{2}$ Department of Biology, Massachusetts Institute \\ of Technology, Cambridge, Massachusetts 02139, USA
}

Successful cellular reproduction requires accurate duplication and partitioning (segregation) of the genome. Failure to correctly partition the sister genomes results in aneuploidy. The consequences of these errors range from loss of normal cellular function (e.g., the loss of normal growth controls in tumor cells) to cell death. In prokaryotes with a single chromosome, partitioning failures are fatal for at least one of the two daughter cells; a so-called anucleate cell forms when one daughter receives no chromosome and the other daughter receives two chromosomes.

Several findings in recent years have fundamentally altered our view of chromosome partitioning in prokaryotes (for review, see Gerdes et al. 2000; Gordon and Wright 2000; Hiraga 2000; Møller-Jensen et al. 2000; Donachie 2001; Sawitzke and Austin 2001). The flurry of new observations was ignited by adaptation of cell biological techniques used in eukaryotes (immunofluorescence, GFP, and fluorescent in situ hybridization) for use in prokaryotes (Harry et al. 1995; Pogliano et al. 1995; Webb et al. 1995; Niki and Hiraga 1998). This review focuses on chromosome partitioning in bacteria that have a single circular chromosome, specifically, the gram-positive organism, Bacillus subtilis, and the gramnegative organisms, Escherichia coli and Caulobacter crescentus. In these bacteria, DNA replication initiates once per cell division cycle from a specific chromosomal locus, ori $C$, and proceeds bidirectionally to terminate in a defined region opposite the origin, $\operatorname{ter} C$ (Fig. 1). The basic components of the DNA replication machinery are highly conserved in bacteria (Kornberg and Baker 1992); in fact, these basic components are functionally conserved from bacteria to mammals (Baker and Bell 1998).

Fundamental differences exist between chromosome partitioning in eukaryotes and prokaryotes. In eukaryotes, chromosomes are duplicated in $\mathrm{S}$ phase, and sister chromosomes remain together during $\mathrm{G}_{2}$. Chromosome partitioning occurs during $M$ phase, when sister chromosomes are lined up on a metaphase plate, separated from each other, and finally segregated in opposite directions

${ }^{3}$ Corresponding author.

E-MAIL adg@mit.edu; FAX (617) 253-2643.

Article and publication are at http://www.genesdev.org/cgi/doi/10.1101/ gad.913301. by the combined action of the microtubular spindle and mitotic motors.

In contrast to the temporal separation of chromosome replication and partitioning in eukaryotes, regions of the bacterial chromosome, starting with the origin, appear to be partitioned soon after duplication, whereas the remainder of the chromosome awaits replication (Glaser et al. 1997; Gordon et al. 1997; Lewis and Errington 1997; Lin et al. 1997; Mohl and Gober 1997; Webb et al. 1997, 1998; Niki and Hiraga 1998; Sharpe and Errington 1998; Teleman et al. 1998; Jensen and Shapiro 1999; Niki et al. 2000). Thus, in bacteria, DNA replication, chromosome refolding, and chromosome partitioning are concurrent. Given these differences, it is not surprising that there is no evidence that bacteria contain eukaryotic-like mitotic spindles or mitotic motors. As discussed below, it appears that bacteria with circular chromosomes probably power chromosome partitioning differently from eukaryotes. This may be possible because of the much smaller distances that chromosomes move in bacteria.

Many bacteria, including B. subtilis and E. coli, are capable of dividing in one-half to one-third of the time it takes to duplicate the genome. To accomplish this, new rounds of DNA replication are initiated before a previous round is completed, giving the replication cycle a head start on the division cycle. This results in cells with multiple bidirectional DNA replication forks (so-called multifork replication), multiple copies of $\operatorname{oriC}(2,4$, or 8), but only a single, unduplicated terminus region (Fig. 2). Soon after duplication, sister origins are each partitioned in opposite directions. Thus, during multifork replication, bacteria contain positional information regarding not only the current medial division site, but also the future division planes (the cell quarters and cell eighths). Other bacteria, for example $C$. crescentus, are not known to be capable of multifork replication and do not have more than two copies of the origin per cell. Recent studies have revealed common mechanisms involved in chromosome partitioning, along with differences in some of the details between organisms.

This review summarizes the following recent findings that have contributed new insights into the mechanism by which bacteria accomplish accurate chromosome partitioning. First, the bacterial chromosome has a defined orientation within cells, and individual regions move 


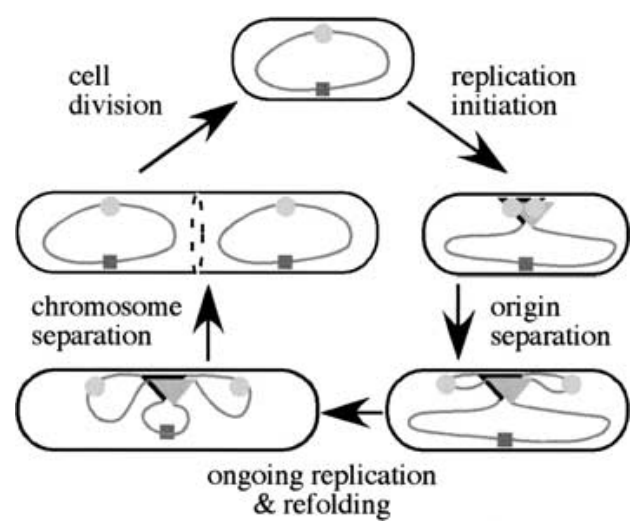

Figure 1. A simplified model of the bacterial cell cycle. DNA (dark gray lines), origin (oriC, gray circles), terminus (ter $C$, dark gray square), replisome (overlapping triangles, one for each replication fork), cytokinetic ring (dashed line). In this model, DNA replication initiates at or near mid cell. The sister origins rapidly separate from each other and become anchored on opposite halves of the cell. DNA replication continues followed closely by refolding of newly replicated DNA until there are two complete and separate chromosomes. Finally, the cell divides medially. The model is simplified to ignore multifork replication.

during the cell cycle to achieve this orientation. Soon after duplication, the two new origins move to positions in opposite halves of the cell, whereas the unduplicated terminus region is centrally located (Fig. 1) (Gordon et al. 1997; Webb et al. 1997, 1998; Niki and Hiraga 1998; Teleman et al. 1998; Jensen and Shapiro 1999; Niki et al. 2000). Second, B. subtilis and probably E. coli have a centrally located replication factory through which the DNA template moves during duplication (Lemon and Grossman 1998, 2000; Koppes et al. 1999|. Third, homologs of eukaryotic structural maintenance of chromosomes (SMC) proteins are necessary for accurate chromosome partitioning (Niki et al. 1991; Britton et al. 1998; Moriya et al. 1998; Jensen and Shapiro 1999; Graumann 2000); in addition, homologs of plasmid partition-

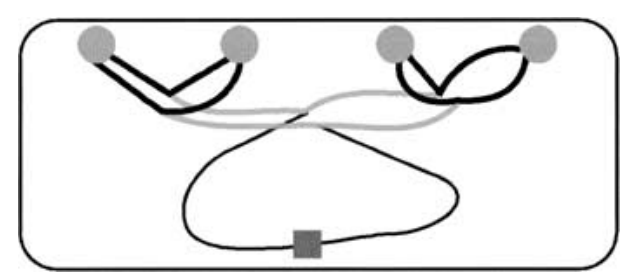

Figure 2. A model of a circular chromosome that is undergoing multifork replication in a rod-shaped bacterium. The cell contains four copies of the origin region (gray circles). The initial round of replication in the middle is duplicating the parental chromosome (thin black) to generate the gray copies. A second round has begun at the quarters, duplicating the daughters (gray) to generate the granddaughters (thin black). The cell contains four copies of the origin region (gray circles), located approximately at the one-, three-, five-, and seven-eighth positions along the cell length, and a single copy of the terminus region (dark gray square) located near mid cell. ing proteins enhance this accuracy (Ireton et al. 1994; Mohl and Gober 1997). Finally, several terminus regionspecific mechanisms exist to ensure that once replicated, the sister terminus regions are properly separated when medial cell division is complete (Baker 1995; Hill 1996; Bussiere and Bastia 1999; Donachie 2001; Lemon et al. 2001; Sawitzke and Austin 2001).

\section{Chromosome orientation}

Evidence that the chromosome has a defined orientation within the cell has put to rest the notion that bacteria are simply bags of protein and DNA with little internal organization (Fig. 1) (Levin and Grossman 1998; Losick and Shapiro 1999|. Origin region positioning has been determined in B. subtilis, E. coli, and C. crescentus in both live and fixed cells using a variety of methods and various origin region markers. Soon after duplication, origin regions separate from each other and move to opposite sides of the cell (Glaser et al. 1997; Gordon et al. 1997; Lewis and Errington 1997; Lin et al. 1997; Mohl and Gober 1997; Webb et al. 1997, 1998; Niki and Hiraga 1998; Sharpe and Errington 1998; Teleman et al. 1998; Jensen and Shapiro 1999; Niki et al. 2000). The origin regions of $E$. coli and $C$. crescentus appear to then reside close to opposite cell poles for the bulk of the cell cycle (Gordon et al. 1997; Niki and Hiraga 1998; Jensen and Shapiro 1999; Niki et al. 2000). The B. subtilis sister origins, however, are located at or near the cell quarter positions (Sharpe and Errington 1998; Lin 1999), sites that will become mid cell following cell division. Presently, there is conflicting evidence as to whether DNA replication initiates at mid cell (or positions that will become mid cell) or near a cell pole (Imai et al. 2000; Lemon and Grossman 2000). However, considering the position of the DNA polymerase (see below), the simplest model is that the origin is duplicated at mid cell. Long after the sister origins have taken up residence in opposite halves of the cell, the unduplicated terminus region remains at mid cell (Gordon et al. 1997; Webb et al. 1997, 1998; Niki and Hiraga 1998; Teleman et al. 1998; Jensen and Shapiro 1999; Niki et al. 2000; Lemon et al. 2001). Just before medial cell division, the two new copies of the terminus region are found flanking mid cell. Following division, the terminus appears to be repositioned from the cell pole to mid cell in daughter cells (Niki et al. 2000). How this occurs is not clear, but it suggests the possibility that the terminus region contains its own positioning information.

In $B$. subtilis and E. coli, chromosomal regions between the origin and terminus regions are generally found between them in the cell (Teleman et al. 1998; Niki et al. 2000). The molecular details of how the origin and terminus are positioned are not known; however, the origin regions of $B$. subtilis and E. coli are enriched in membrane fractions, as is the B. subtilis terminus (Winston and Sueoka 1980; Firshein 1989; Kornberg and Baker 1992; Sueoka 1998). These findings are consistent with a model in which the origin and terminus regions of the chromosome are membrane anchored, 
whereas intervening regions have more positional flexibility.

\section{A central replication factory}

The visualization of DNA polymerase in live cells of $B$. subtilis has altered our view of chromosome partitioning (Lemon and Grossman 1998, 2000). B. subtilis has a centrally located replisome (the multiprotein complex, including the polymerase, helicase, and associated proteins that are present at the replication forks) through which the DNA template is pulled, duplicated, and released outward during replication. A functional fusion of the catalytic subunit of $B$. subtilis DNA polymerase to GFP (PolC-GFP) is located at or near mid cell in live cells during DNA replication (Lemon and Grossman 1998). PolC-GFP foci disappear when ongoing rounds of DNA replication finish, and the number of foci per cell increases as expected during multifork replication. In addition, other subunits of DNA polymerase, including $\tau$, which dimerizes the catalytic subunits, and $\delta^{\prime}$, a component of the sliding clamp loader (for reviews, see Kornberg and Baker 1992; Yoshikawa and Wake 1993; Kelman and O'Donnell 1995; Baker and Bell 1998), localize in a similar manner (Lemon and Grossman 1998).

Another set of experiments in B. subtilis indicates that after the initiation of replication, the DNA template moves to the central DNA polymerase, is replicated, and then the two copies of each region move in opposite directions away from the cell center. Specific regions of the chromosome can be visualized using a fusion of Lac repressor to GFP (LacI-GFP) bound to an array of Lac operators (lacO) inserted into the desired location on the chromosome (Robinett et al. 1996; Straight et al. 1996; Gordon et al. 1997; Webb et al. 1997; Belmont and Straight 1998). In a roughly synchronous population of cells, a chromosomal region midway between oriC and ter $C$ appears to move to the replisome just before replication (Lemon and Grossman 2000).

In addition, when replication is arrested in a specific region of the chromosome, that region is found at mid cell, coincident with the centrally located replisome (Lemon and Grossman 2000). Shortly after release of the replication arrest, there are two copies of the region on opposite halves of the cell whereas the replisome remains located near mid cell (Lemon and Grossman 2000). The replication arrest experiments took advantage of elegant work characterizing the effects of amino acid starvation on DNA replication. On amino acid starvation (induction of the stringent response), a reversible DNA replication arrest occurs in B. subtilis in regions $\sim 100-130 \mathrm{kbp}$ to the left (LSTer, left stringent terminus region) and $\sim 150-200 \mathrm{kbp}$ to the right (RSTer) of the origin of replication (Levine et al. 1991, 1995; Autret et al. 1999). Replication resumes in the STer regions when amino acids are added back to the cells. Starvation for an amino acid activates the production of the alarmone, (p)ppGpp by the relA gene product, which induces the pleiotropic stringent response in many bacteria (Cashel et al. 1996; Wendrich and Marahiel 1997). The stringent arrest of DNA replication at sites away from the origin has only been characterized in B. subtilis.

Recent evidence indicates that $E$. coli also has a centrally located replication factory. Newly duplicated DNA, detected by pulse labeling with $\left[{ }^{3} \mathrm{H}\right]$ thymidine, is located at cell center in a majority of cells, indicating that DNA replication occurs centrally (Koppes et al. 1999|. Additional supporting evidence is provided by the localization of SeqA, a protein that binds newly duplicated hemimethylated DNA at GATC sites (Slater et al. 1995) during the few minutes before methylation of the newly synthesized DNA strand (Campbell and Kleckner 1990). Note that B. subtilis does not have SeqA or methylation at GATC sites (Kunst et al. 1997). SeqA forms either one centrally located focus or two foci, one in each half of the cell, and focus formation depends on the GATC methylase (Hiraga et al. 1998; Onogi et al. 1999) and DNA replication (Hiraga et al. 2000). Although SeqA also specifically binds to the origin or replication (Slater et al. 1995), SeqA foci do not appear to colocalize with oriC (Hiraga et al. 1998). It appears that the bulk of the 1000 SeqA molecules (Slater et al. 1995) in an E. coli cell bind to newly duplicated DNA that has just exited the replisome (Brendler et al. 2000). Brendler et al. (2000) propose that SeqA, a membrane-associated protein, helps organize and tether newly duplicated DNA against the cytoplasmic face of the membrane in a manner that facilitates partitioning. Eventually, the central SeqA focus duplicates, the two new foci flank the FtsZ ring (presumed cytokinetic ring), and then the SeqA foci rapidly move to opposite cell quarter positions (Hiraga et al. 1998, 2000; Onogi et al. 1999). It has been suggested that this SeqA movement represents translocation of the replication factory before completion of chromosome duplication (Hiraga 2000; Hiraga et al. 2000). Alternatively, it may be that the SeqA duplication and separation corresponds with that of the terminus region. It would be interesting to compare the position of the terminus and SeqA in E. coli.

The position of newly duplicated DNA, as indicated by SeqA, and the similarity between the localization patterns of SeqA in E. coli (Hiraga et al. 1998) and DNA polymerase in B. subtilis (Lemon and Grossman 1998) are consistent the notion that $E$. coli has a centrally located replication factory. However, definitive localization of the E. coli replicative DNA polymerase will be the critical factor allowing us to finally distinguish between the various models for DNA replication and chromosome partitioning currently in the literature. Replication factories that spool DNA appear to be a common theme in biology because evidence exists that eukaryotic DNA polymerases are in foci that are probably stationary (Hozak et al. 1993; Newport and Yan 1996; Cook 1999; Leonhardt et al. 2000; references therein).

\section{The extrusion-capture model}

In light of the position of DNA polymerase, we propose that $B$. subtilis, and probably many bacteria, harness the energy released during replication by the replication fac- 
tory to power, at least in part, partitioning of newly duplicated chromosomal regions (Lemon and Grossman 1998, 2000). In this model (Fig. 3), the replisome pulls the DNA template into the cell center, duplicates it, and then releases the products into opposite halves of the cell. Movement away from the replication factory is kept orderly by proteins involved in chromosome organization, compaction, and supercoiling. We speculate that a transient association of newly duplicated DNA with the inner face of the membrane, as suggested for E. coli (Brendler et al. 2000), or a system for imparting increased structure and rigidity to the origin region, possibly Spo0J-parS (see below), might facilitate poleward origin region migration.

For years, the replicative DNA polymerase was thought to move itself along the DNA, like a train on a track. However, our current view is that the replisome is the engine involved in spooling the chromosome through a replication factory. In thinking about the replisome and polymerases as motor proteins, it is worth noting that the force generated during transcription by a single stationary RNA polymerase is $\sim 25$ picoNewtons (Gelles and Landick 1998; Wang et al. 1998), indicating that RNA polymerase is a more powerful motor than either myosin or kinesin (for reviews, see Block 1998; Goldman 1998; Cook 1999; Mehta et al. 1999; Vale and Milligan 2000). The rate of replication is $\sim 10$-fold greater than the rate of transcription, and together, DNA polymerase and the replicative DNA helicase likely contribute to template movement.

A critical aspect of the extrusion-capture model is that once released outward from the replisome, the origins are captured and held on opposite sides of the cell, possibly via a membrane-associated anchor. In this model, it is possible that the DNA sites and proteins involved in movement are distinct from those involved in positioning (in contrast to eukaryotic centromeres). However, for simplicity we favor a model in which the origin itself, or sites near the origin, contain information needed for proper positioning. We postulate that some of the proteins involved in the initiation of replication are also involved in origin positioning. In B. subtilis, one such candidate is the $d n a B$ gene product (not related to the helicase encoded by E. coli dnaB). B. subtilis dnaB encodes a membrane protein that is required for the initia-

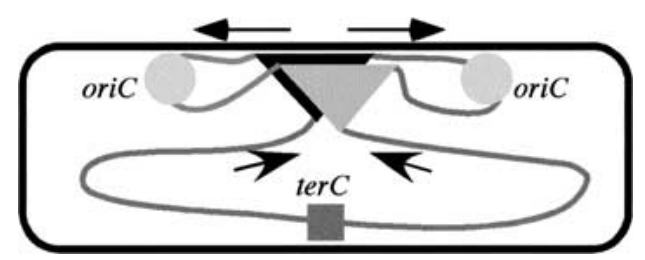

Figure 3. The extrusion-capture model for bacterial chromosome partitioning. After the origin region is replicated, the two sister origins (light gray circles) are extruded from (arrows pointing toward cell poles) the centrally located replisome (overlapping triangles) and captured on opposite halves of the cell at or near the cell quarters. The terminus region (dark gray square) remains at mid cell until it is duplicated. tion of replication and for enrichment of the origin region in membrane fractions (Winston and Sueoka 1980; Hoshino et al. 1987; Sueoka 1998). It participates (with two other proteins, DnaD and DnaI) in loading of the replicative helicase (B. subtilis DnaC) (Bruand et al. 1995) and is found in other low G + C, gram-positive bacteria, including Staphylococcus aureus, Enterococcus faecalis, but not in E. coli and other gram-negative bacteria. Perhaps B. subtilis DnaB and/or other initiation proteins help to establish (capture) and/or maintain positioning of the origin region at the cell quarters. These or additional factors might also contribute to the rapid movement of sister origin regions, possibly by restricting movement in two dimensions.

After origin region capture, the bulk of chromosome partitioning can be achieved by a combination of ongoing DNA replication and chromosome recompaction/refolding. Finally, specialized mechanisms exist to ensure that sister terminus regions are not caught in the division septum (see below).

\section{Bacterial SMC and chromosome compaction}

Chromosome compaction and organization are clearly important for partitioning, and deletion of genes whose products play a role in these processes can have devastating effects. SMC proteins, first identified in eukaryotes, also function in chromosome compaction and segregation in bacteria and archaea (for review, see Graumann 2001). Many bacteria encode a single SMC (Britton et al. 1998; Melby et al. 1998; Moriya et al. 1998; Hirano 1999l, and most of those that lack SMC instead encode a homolog of E. coli MukB, which is a functional analog of SMC (Melby et al. 1998). SMC proteins consist of an amino-terminal nucleoside triphosphate (probably ATP) binding domain, two coiled-coil domains separated by a flexible hinge, and a carboxy-terminal domain, which binds DNA and has a conserved "DA-box" motif (for reviews, see Koshland and Strunnikov 1996; Hirano 1999; Graumann 2001). B. subtilis SMC is an ATPase, binds DNA, and functions as an antiparallel homodimer with the ATP binding site made up of surfaces from both the amino- and carboxy-terminal domains with one domain contributed by each subunit of the homodimer (Hirano and Hirano 1998; Melby et al. 1998; van den Ent et al. 1999; Löwe et al. 2001). E. coli MukB has a similar domain structure but lacks the DA-box. Electron microscopy of B. subtilis SMC and E. coli MukB reveals strikingly similar structures: two globular domains separated by a long rod-like domain with a flexible hinge in the middle (Niki et al. 1992; Melby et al. 1998).

smc null mutants appear to have a defect in chromosome organization that results in a secondary defect in chromosome partitioning. B. subtilis smc null mutants are temperature-sensitive lethal in rich growth medium. Under permissive conditions, $\sim 10 \%$ of the smc mutant cells are anucleate, and the rest frequently display abnormal nucleoid morphology and mislocalization of the origin region (Britton et al. 1998; Graumann et al. 1998; Moriya et al. 1998; Graumann 2000). (The bacterial chro- 
mosomal mass, which during growth consists of $1+$ genome equivalents and associated proteins, is referred to as the nucleoid.)

E. coli MukB acts in concert with two other proteins, MukE and MukF. mukE and mukF are in an operon with mukB (Yamanaka et al. 1996), and a complex of MukB, MukE, and MukF can be immunoprecipitated (Yamazoe et al. 1999). Null mutants in any of these genes display temperature-sensitive lethality (Niki et al. 1991; Yamanaka et al. 1996). At permissive temperatures, mukB mutants produce $\sim 5 \%$ anucleate cells (Niki et al. 1991).

C. crescentus smc null mutants are not viable in rich medium and are temperature sensitive in minimal medium (grows at $\leq 25^{\circ} \mathrm{C}$; Jensen and Shapiro 1999). Under restrictive conditions, $C$. crescentus mutants have abnormal nucleoids, and the origin region is mislocalized in a subpopulation of cells (Jensen and Shapiro 1999). However, in contrast to the B. subtilis smc (Britton et al. 1998; Moriya et al. 1998) and E. coli mukB (Niki et al. 1991) mutants, the $C$. crescentus smc mutant produces few anucleate cells under permissive conditions (Jensen and Shapiro 1999). Instead, mutants arrest at a predivisional cell stage, suggesting that $C$. crescentus has a cell cycle checkpoint for detecting disruption of chromosome organization (Jensen and Shapiro 1999).

Based on structural similarity with motor proteins, it was originally postulated that MukB would act as a partitioning motor. Recent data have altered this view. First, the antiparallel arrangement of the subunits in the homodimer argues against directional movement (Melby et al. 1998). Second, time-lapse microscopy reveals that the $B$. subtilis origin regions move similarly in smc null and wild-type cells (Graumann 2000). Third, mutations in topoisomerase I (top $A$ ) suppress the $\operatorname{muk} B$ phenotype (Sawitzke and Austin 2000), and mukB strains are hypersensitive to gyrase inhibitors (Weitao et al. 1999; Sawitzke and Austin 2000). Topoisomerase I mutants have an increase in the level of negative supercoiling because of the unopposed action of gyrase, whereas gyrase inhibitors decrease the amount of negative supercoiling. The suppression of mukB by top $A$ has led to a new model in which the function of MukB is to organize the chromosome into a higher order structure by constraining supercoils (Holmes and Cozzarelli 2000; Sawitzke and Austin 2000). Additionally, the appearance and positioning of SeqA foci is abnormal in mukB null mutants, supporting a role for MukB in chromosome organization (Hiraga et al. 1998; Onogi et al. 1999). The partitioning defect in mukB and smc mutants is probably a secondary consequence caused by defects in chromosome compaction and organization.

In addition to SMC (MukB), other proteins are involved in chromosome compaction and organization. Many bacteria have one or more abundant, basic, sequence nonspecific DNA binding proteins involved in chromosome organization, e.g., the histone-like E. coli $\mathrm{HU}$ and B. subtilis HBsu proteins (for review, see Trun and Marko 1998). However, the primary structural unit of bacterial chromosome organization and compaction remains elusive. There is no evidence for eukaryotic-like nucleosomes, yet somehow, bacteria efficiently package a large amount of DNA into a small volume. For example, the $4200 \mathrm{~kb}$ B. subtilis chromosome, with a contour length of $\sim 1 \mathrm{~mm}$, fits neatly into a cell $2-4 \mu \mathrm{m}$ in length and $\sim 0.5 \mu \mathrm{m}$ in diameter. In addition to bulk chromosome organization, recent models have suggested that specific chromosomal regions may undergo additional organization, such as the proposed effect of SeqA on newly replicated DNA (Brendler et al. 2000).

\section{Par proteins and origin region partitioning}

Chromosomal homologs of the plasmid Par system enhance accurate chromosome partitioning; however, their exact function remains to be determined. One of several possibilities is that the chromosomal Par system organizes the origin region into a higher order structure, not present in the rest of the chromosome, which facilitates partitioning. The Par system was first identified in the low copy E. coli plasmids, $\mathrm{P} 1$ (parABS) and $\mathrm{F}(\operatorname{sop} A B C)$ (Ogura and Hiraga 1983; Abeles et al. 1985). Several unicopy or low copy plasmids depend on homologs of ParA, ParB, and the cis-acting parS site for stable maintenance. There are several recent detailed reviews of the Par system (Gerdes et al. 2000; Gordon and Wright 2000; Hiraga 2000; Møller-Jensen et al. 2000) and what follows is a brief summary.

The two par genes are in an operon adjacent to the cis-acting DNA site, parS. The ParA family member is a Walker-type ATPase and a DNA-binding protein, often functioning as a transcriptional repressor of the par $A B$ operon. ParA interacts with the ParB-parS complex and is required for accurate plasmid partitioning. The ParB family member binds to pars and modulates both the ATPase and transcriptional repressor activity of ParA. It appears that ParB binding to parS can nucleate ParB binding over a large region of adjacent DNA. This nucleation can result in transcriptional silencing of adjacent genes. Exactly how the various activities of ParA and ParB-parS achieve plasmid partitioning is not clear, though part of the process must involve plasmid movement to, and positioning at, defined cellular positions. P1 and F plasmids localize to mid cell and after duplication, to both cell quarter positions (future mid-cell positions) (Gordon et al. 1997; Niki and Hiraga 1997). Deletion of the par cassette $(\operatorname{sop} A B C)$ from the mini-F genome results in random plasmid localization, primarily in regions without nucleoids in fixed cells (Niki and Hiraga 1997). P1 ParB localizes as discrete foci with a pattern similar to that of the plasmid. ParB focus formation requires parS, and proper ParB-parS localization depends on parA (Erdmann et al. 1999|. New evidence indicates that ParA is membrane associated; therefore, it might help tether the ParB-parS complex at specific cellular positions (Lin and Mallavia 1998). Most models presume that there is a host receptor for the plasmid Par complex, but one has yet to be identified. Recent experiments show that some multicopy plasmids also localize, as clusters, at mid cell and cell quarters (Pogliano et al. 2001). These plasmids 
lack the Par system, and how they localize is of great interest.

Chromosomal homologs of the plasmid Par system have been identified by sequence analysis in many bacterial species and are uniformly located in the origin proximal region of the chromosome (Ireton et al. 1994; Lin et al. 1997; Mohl and Gober 1997; Lin and Grossman 1998; Gerdes et al. 2000; Hiraga 2000; Yamaichi and Niki 2000). Analysis of ParA and ParB sequences shows that each protein family consists of two subfamilies, the chromosomal Par proteins and the plasmid Par proteins (Gerdes et al. 2000; Yamaichi and Niki 2000). Interestingly, E. coli and Haemophilus influenzae, which encode MukBEF homologs rather than SMC homologs, both lack ParAB family members (Britton et al. 1998; Gerdes et al. 2000).

The B. subtilis ParA and ParB homologs were first identified for their regulatory role during initiation of sporulation, a fact that is reflected in their names, Soj and Spo0J (Piggot and Coote 1976; Ireton et al. 1994; Quisel et al. 1999; Quisel and Grossman 2000). Spo0J (ParB) binds to at least eight parS sites located in the origin proximal $20 \%$ of the chromosome (Lin and Grossman 1998). Spo0J binding to parS in the origin proximal region forms a large nucleoprotein complex that is visible using either immunofluorescence or a functional Spo0J-GFP fusion, which is a good marker for origin position (Glaser et al. 1997; Lewis and Errington 1997; Lin et al. 1997; Sharpe and Errington 1998; Teleman et al. 1998). The appearance of a single Spo0J focus per origin region suggests that SpoOJ binding to the parS sites organizes the origin region in such a way to bring most or all of the pars sites together. Note that the most distal parS sites are $\sim 800 \mathrm{kbp}$ apart (Lin and Grossman 1998).

Spo0J binding to parS somehow contributes to accurate chromosome partitioning. spoOJ null mutants produce 1\%-2\% anucleate cells (Ireton et al. 1994) and a spoOJ smc double mutant has a synthetic defect in partitioning (Britton et al. 1998). Together, Spo0J and parS can stabilize a low copy plasmid in B. subtilis (Lin and Grossman 1998). Although null mutants of the B. subtilis parA homolog, soj (suppressor of spoOJ during sporulation), have little or no chromosome partitioning defect (Ireton et al. 1994), Soj enhances the ability of SpoOJ-parS to stabilize a plasmid (Lin and Grossman 1998) and may contribute to the formation of Spo0J foci (Marston and Errington 1999). Spo0J, parS, and Soj can also partially substitute for $\operatorname{sop} A B C$ to stabilize and properly position a mini-F plasmid in E. coli (Yamaichi and Niki 2000). This suggests that either the Par system alone is sufficient for partitioning of a plasmid or that any additional host factors are highly conserved.

It has been tempting to call the chromosomally encoded ParB (SpoOJ) a centromere-binding protein and its binding site, parS, a bacterial centromere. However, we prefer avoiding the term centromere when describing bacterial chromosome segregation. For many, the term centromere implies a cis-acting sequence to which proteins involved in moving the chromosome attach and perhaps more significantly, implies that parS is critical for chromosome partitioning. Although the Par system plays an important role in chromosome partitioning, it is clearly not essential, except in C. crescentus. Overexpression of ParA or ParB in C. crescentus disrupts normal ParA and ParB localization and results in approximately 5\% anucleate cells (Mohl and Gober 1997). It is possible that many conserved bacterial proteins involved in chromosome partitioning that are nonessential in other bacteria will be essential in $C$. crescentus because of its rigid cell cycle and possible cell cycle checkpoints (Jensen and Shapiro 1999). In stark contrast to C. crescentus, E. coli and $H$. influenzae have no parABS. In addition, although $B$. subtilis has parABS, origin region localization is similar in spo0J(parB) null mutants and wild-type cells (Webb et al. 1997; Lin 1999), and origin region movement is unaffected in a majority of spoOJ cells (Webb et al. 1998), inconsistent with the notion that ParB (Spo0J) functions as a centromere-binding protein. Thus, to avoid unwarranted inferences, we suggest avoiding the term centromere until there is evidence for a direct analogy to its meaning in eukaryotes.

The nucleoprotein structure formed when SpoOJ binds to all or most of the parS sites may impart to the origin region a unique higher order chromosome organization. Several recent findings support this model. During sporulation of a spoOJ soj double mutant, multiple foci of both the origin and terminus region are observed, indicating an increase in chromosome number (Webb et al. 1997). More recently, flow cytometry data indicate that overreplication occurs in spoOJ mutants during exponential growth (Imai et al. 2000). Spo0J might influence the frequency of initiation of DNA replication by bringing the origin proximal $20 \%$ of the chromosome together in a nucleoprotein structure that resists reinitiation. Separation and repositioning of the chromosome origin region appears to be more complex than plasmid positioning, and we expect that there will therefore be a number of proteins and DNA sites that ensure accurate origin region partitioning. Once the bulk of the two duplicated chromosomes have been partitioned, a bacterial cell still has a few terminus region-specific problems to solve before it has two complete and separate chromosomes.

\section{Termination of DNA replication and separation of sister termini}

Late in the cell cycle, long after the sister origins have taken up residence in opposite halves of the cell, the terminus region is finally duplicated. Recently, significant progress has been made in elucidating events required to complete replication and partition of the terminus region. Both $B$. subtilis and $E$. coli have replication termination proteins and cis-acting DNA sites, Ter, to ensure that DNA replication terminates in a region of the chromosome roughly opposite the origin (at $\sim 180^{\circ}$ on a $360^{\circ}$ circular chromosome) (for reviews, see Baker 1995; Hill 1996; Bussiere and Bastia 1999|. Although many circular genomes appear to have termination systems, it is the organization, and not the protein or DNA site, that appears to be conserved. Deletion of chromo- 
somal termination systems alone does not cause an obvious defect in growth or chromosome partitioning (Iismaa and Wake 1987). However, B. subtilis rtp (replication termination protein) mutations exacerbate the partitioning defects caused by mutations in other terminus-related partitioning systems (spoIIIE and ripX, see below), indicating that accurate termination of DNA replication facilitates accurate partitioning (Lemon et al. 2001). However, as described below, completion of DNA replication is not sufficient to guarantee two separate chromosomes.

Replication of circular double-stranded DNA results in topologically linked products that must be decatenated to complete partitioning (Fig. 4A). In E. coli Topo IV, a type II topoisomerase encoded by parC and parE, is required for the final decatenation of sister chromosomes and is essential for cell viability (Kato et al. 1990; Adams et al. 1992; Peng and Marians 1993; Ullsperger and Cozzarelli 1996). Homologs of parC and parE are present in many bacteria.

Homologous recombination between newly duplicated regions of sister chromosomes can produce chromosome dimers of circular chromosomes (Fig. 4B). A dimer is obviously incompatible with chromosome partitioning. Many circular genomes, both bacterial and plasmid, encode dimmer-to-monomer resolution systems. Perhaps the best-studied chromosomal system is from $E$. coli in which two tyrosine site-specific recombinases, XerC and XerD, act on a specific DNA sequence, the dif site, located in the terminus region (Hill 1996). Recently, the B. subtilis dif site and XerCD homologs, CodV and RipX, were identified and shown to function in dimer resolution (Sciochetti et al. 1999, 2001). Deletion of the Xer-dif system from either E. coli or B. sub-
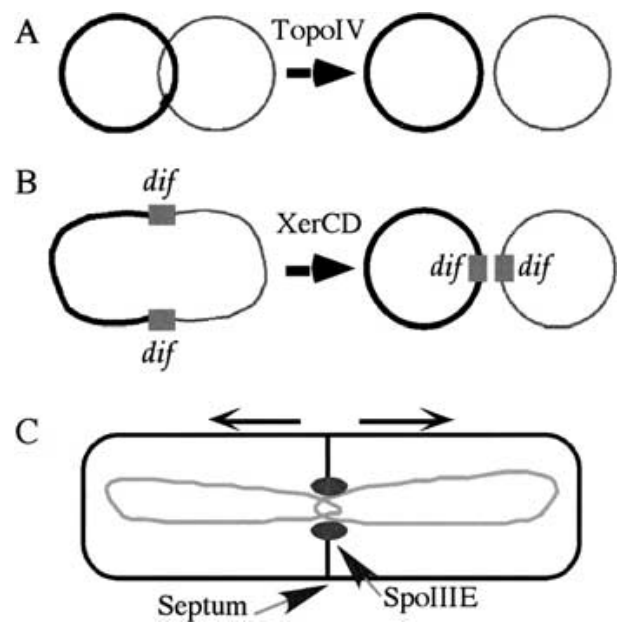

Figure 4. Terminus-specific chromosome partitioning events. (A) Chromosome decatenation. (B) If formed, a chromosome dimer is resolved to two monomers by two site-specific recombinases acting on the dif site in the terminus region. $(C)$ When chromosomes (gray) are trapped in an invaginating division septum (black vertical lines), SpoIIIE (black ovals) pumps the chromosomes out of the way (arrows above cell indicate direction each chromosome will move). tilis results in partitioning defects (Blakely et al. 1991; Kuempel et al. 1991; Sciochetti et al. 1999, 2001; Lemon et al. 2001).

The end result of the Xer-dif site-specific recombination system must be the resolution of chromosome dimers. This could be accomplished by active separation of sister chromosomes after dimers are resolved by recombination, either RecA-mediated homologous recombination or Xer-mediated recombination at dif. In E. coli, there appear to be mechanisms that help to ensure that chromosome dimers are resolved and not created by XerCD activity at dif. dif recombination appears to depend on dimer formation, as no Xer activity is detected in $r e c A$ null cells (homologous recombination requires recA) (Perals et al. 2001). Additionally, FtsK, a protein required for cell division that is located at the leading edge of the invaginating division septum, is required for activation of the Xer-dif system, suggesting that a dimer must be trapped in the closing septum to activate Xer recombination (Begg et al. 1995; Liu et al. 1998; Yu et al. 1998; Recchia et al. 1999; Steiner et al. 1999). The Cterminal domain of FtsK is required for efficient dif sitespecific recombination (Recchia et al. 1999; Steiner et al. 1999) and is conserved in two B. subtilis proteins, SpoIIIE and YtpT (a protein similar to SpoIIIE, but with no known function). Despite this similarity, neither SpoIIIE nor YtpT appears to have a role in B. subtilis dif recombination (Sciochetti et al. 2001). It is possible that $B$. subtilis ensures resolution of dimers by physically separating sisters after recombination.

\section{Post-septation partitioning}

Many bacteria appear to have a mechanism for postseptational partitioning, such that any chromosome that might be caught in the newly formed septum can still be successfully partitioned. Members of a family of proteins, represented by B. subtilis SpoIIIE and E. coli FtsK, localize to the leading edge of the septum and function as ATP-dependent DNA pumps (Wu and Errington 1994; Wu et al. 1995; Wang and Lutkenhaus 1998; Bath et al. 2000). The amino-terminal domains of SpoIIIE and FtsK are required for localization to the leading edge of the division septum (Wu and Errington 1997; Wang and Lutkenhaus 1998). The carboxy-terminal cytoplasmic domain of SpoIIIE tracks along DNA in an ATP-dependent manner in vitro (Bath et al. 2000). This supports a model in which SpoIIIE and related proteins act as a pump to move chromosome(s) out of the closing division septum (Bath et al. 2000). This mechanism is required during $B$. subtilis sporulation when the asymmetric sporulation septum forms with approximately one-third of a chromosome partitioned to the cell destined to become the spore (the forespore). SpoIIIE is required to complete partitioning of the rest of a chromosome into the forespore (Fig. 4C) (Wu and Errington 1994; Wu et al. 1995). Most bacteria with a SpoIIIE homolog do not sporulate (e.g., E. coli). Although SpoIIIE is not required during exponential growth (medial division), it is important in situations in which the normal coupling between chromo- 
some partitioning and division is perturbed (Sharpe and Errington 1995; Britton and Grossman 1999). For example, a spoIIIE smc double mutant is synthetically lethal (Britton and Grossman 1999). SpoIIIE-type proteins appear to serve as a backup mechanism used to salvage an otherwise terminal event when a partitioning failure leaves part of a chromosome caught in the division septum.

\section{Summary}

We have proposed that many bacteria harness the energy produced during DNA polymerization by a replication factory to facilitate chromosome partitioning. As illustrated in this review, a number of proteins and DNA sites, particularly those involved in chromosome organization and compaction, are needed for accurate chromosome partitioning. Partitioning of circular bacterial chromosomes can be considered to occur in several phases. First, newly duplicated origin regions move away from each other and away from the central replisome to opposite halves of the cell where they are then somehow maintained at or near the cell quarters. Second, the bulk of chromosomal DNA, which resides between the origin and terminus, is replicated, refolded, and partitioned. Third, DNA replication terminates, sister chromosomes are decatenated, dimers are resolved to monomers (when necessary), and sister termini move to either side of the division septum. After cell division, the process culminates with the repositioning of the terminus to mid cell.

There are many interesting and important questions to be explored in the next few years, including: (1) What DNA sites and proteins are responsible for origin movement and for positioning? (2) Are the sites and proteins used during exponential growth the same as those used during development or entry into stationary phase? (3) How is the terminus region positioned to mid cell after division? (4) What, if any, are the differences in partitioning between bacteria that are (B. subtilis, E. coli) and are not (C. crescentus) capable of multifork replication? (5) Are there differences in chromosome partitioning attributable to differences in the physical shape (e.g., rod vs. sphere) of bacteria? Perhaps one of the most elusive and interesting issues concerns the nature of positional information: How do bacteria know where to put things and how do they know where the middle, quarters, and eighths are?

One of the interesting features of work in bacteria is the vast evolutionary distances that separate model organisms such as E. coli and B. subtilis. We expect that a number of fundamental mechanisms are conserved over such distances, including the use of replication factories. However, it is equally anticipated that some of the details will be different. At first glance it is not always obvious when a mechanism is fundamental versus when it is more family specific. This can result in radically different models and useful debate.

B. subtilis and E. coli represent two families of bacteria that include a number of human pathogens. For example, B. subtilis is a member of the low $\mathrm{G}+\mathrm{C}$ content family along with Staphylococcus, Streptococcus, Enterococcus, and Clostridia, whereas E. coli, itself a potential pathogen, belongs to the $\gamma$-proteobacteria family along with Salmonella and Shigella. Our increasing understanding of chromosome partitioning and the cell cycle as a whole in these bacteria has begun to elucidate both important similarities and differences among eukaryotes. Where we find differences in critical cell cycle mechanisms, we also find potential drug targets.

It is apparent that many of the proteins and mechanisms that are conserved among bacteria are also conserved between eukaryotes and prokaryotes, for example, SMC and the replication factories. Therefore, studies of these basic processes in bacteria have the potential to provide insights into fundamental mechanisms for maintaining genomic integrity in all organisms.

\section{Acknowledgments}

We thank Janet Lindow, Sheila Jaswal, Peter Reddien, and Kate Bacon Schneider for comments on the manuscript. Work in the laboratory of A.D.G. is partially supported by NIH grant GM41934.

\section{References}

Abeles, A.L., Friedman, S.A., and Austin, S.J. 1985. Partition of unit-copy miniplasmids to daughter cells. III. The DNA sequence and functional organization of the P1 partition region. J. Mol. Biol. 185: 261-272.

Adams, D.E., Shekhtman, E.M., Zechiedrich, E.L., Schmid, M.B., and Cozzarelli. N.R. 1992. The role of topoisomerase IV in partitioning bacterial replicons and the structure of catenated intermediates in DNA replication. Cell 71:277288.

Autret, S., Levine, A., Vannier, F., Fujita, Y., and Seror, S.J. 1999. The replication checkpoint control in Bacillus subtilis: Identification of a novel RTP-binding sequence essential for the replication fork arrest after induction of the stringent response. Mol. Microbiol. 31: 1665-1679.

Baker, T.A. 1995. Replication arrest. Cell 80: 521-524.

Baker, T.A. and Bell, S.P. 1998. Polymerases and the replisome: Machines within machines. Cell 92: 295-305.

Bath, J., Wu, L.J., Errington, J., and Wang, J.C. 2000. Role of Bacillus subtilis SpoIIIE in DNA transport across the mother cell-prespore division septum. Science 290: 995-997.

Begg, K.J., Dewar, S.J., and Donachie, W.D. 1995. A new Escherichia coli cell division gene, ftsK. J. Bacteriol. 177: 62116222.

Belmont, A.S. and Straight, A.F. 1998. In vivo visualization of chromosomes using lac operator-repressor binding. Trends Cell Biol. 8: 121-124.

Blakely, G., Colloms, S., May, G., Burke, M., and Sherratt, D. 1991. Escherichia coli XerC recombinase is required for chromosomal segregation at cell division. New Biol. 3: 789798.

Block, S.M. 1998. Kinesin: What gives? Cell 93: 5-8.

Brendler, T., Sawitzke, J., Sergueev, K., and Austin, S. 2000. A case for sliding SeqA tracts at anchored replication forks during Escherichia coli chromosome replication and segregation. EMBO J. 19: 6249-6258.

Britton, R.A. and Grossman, A.D. 1999. Synthetic lethal phe- 
notypes caused by mutations affecting chromosome partitioning in Bacillus subtilis. J. Bacteriol. 181: 5860-5864.

Britton, R.A., Lin, D.C.H., and Grossman, A.D. 1998. Characterization of a prokaryotic SMC protein involved in chromosome partitioning. Genes \& Dev. 12: 1254-1259.

Bruand, C., Ehrlich, S.D., and Janniere, L.J. 1995. Primosome assembly site in Bacillus subtilis. EMBO J. 14: 2642-2650.

Bussiere, D.E. and Bastia, D. 1999. Termination of DNA replication of bacterial and plasmid chromosomes. Mol. Microbiol. 31: 1611-1618.

Campbell, J.L. and Kleckner, N. 1990. E. coli oriC and the dnaA gene promoter are sequestered from dam methyltransferase following the passage of the chromosomal replication fork. Cell 62: 967-979.

Cashel, M., Gentry, D.R, Hernandez, V.J., and Vinella, D. 1996. The stringent response. In Escherichia coli and Salmonella: Cellular and molecular biology (ed. F.C. Neidhardt et al.), pp. 1458-1496. American Society for Microbiology, Washington, D.C.

Cook, P.R. 1999. The organization of replication and transcription. Science 284: 1790-1795.

Donachie, W.D. 2001. Co-ordinate regulation of the Escherichia coli cell cycle or the cloud of unknowing. Mol. Microbiol. 40: 779-785.

Erdmann, N., Petroff, T., and Funnell, B.E. 1999. Intracellular localization of P1 ParB protein depends on ParA and parS. Proc. Natl. Acad. Sci. 96: 14905-14910.

Firshein, W. 1989. Role of the DNA/membrane complex in prokaryotic DNA replication. Ann. Rev. Micro. 43: 89-120.

Gelles, J. and Landick, R. 1998. RNA polymerase as a molecular motor. Cell 93: 13-16.

Gerdes, K., Møller-Jensen, J., and Jensen, R.B. 2000. Plasmid and chromosome partitioning: Surprises from phylogeny. Mol. Microbiol. 37: 455-466.

Glaser, P., Sharpe, M.E., Raether, B., Perego, M., Ohlsen, K., and Errington, J. 1997. Dynamic, mitotic-like behavior of a bacterial protein required for accurate chromosome partitioning. Genes \& Dev. 11: 1160-1168.

Goldman, Y.E. 1998. Wag the tail: Structural dynamics of actomysin. Cell 93: 1-4.

Gordon, G.S. and Wright, A. 2000. DNA segregation in bacteria. Annu. Rev. Microbiol. 54: 681-708.

Gordon, G.S., Sitnikov, D., Webb, C.D., Teleman, A., Straight, A., Losick, R., Murray, A.W., and Wright, A. 1997. Chromosome and low copy plasmid segregation in E. coli: Visual evidence for distinct mechanisms. Cell 90: 1113-1121.

Graumann, P.L. 2000. Bacillus subtilis SMC is required for proper arrangement of the chromosome and for efficient segregation of replication termini but not for bipolar movement of newly duplicated origin regions. J. Bacteriol. 182: 64636471.

2001. SMC proteins in bacteria: Condensation motors for chromosome segregation? Biochimie 83: 53-59.

Graumann, P.L., Losick, R., and Strunnikov, A.V. 1998. Subcellular localization of Bacillus subtilis SMC, a protein involved in chromosome condensation and segregation. J. Bacteriol. 180: 5749-5755.

Harry, E.J., Pogliano, K., and Losick, R. 1995. Use of immunofluorescence to visualize cell-specific gene expression during sporulation in Bacillus subtilis. J. Bacteriol. 177: 3386-3393.

Hill, T.M. 1996. Features of the chromosomal terminus region. In Escherichia coli and Salmonella: Cellular and molecular biology (ed. F.C. Neidhardt et al.), pp. 1602-1614. American Society for Microbiology, Washington, D.C.

Hiraga, S. 2000. Dynamic localization of bacterial and plasmid chromosomes. Annu. Rev. Genet. 34: 21-59.
Hiraga, S., Ichinose, C., Niki, H., and Yamazoe, M. 1998. Cell cycle-dependent duplication and bidirectional migration of SeqA-associated DNA-protein complexes in E. coli. Mol. Cell 1: 381-387.

Hiraga, S., Ichinose, C., Onogi, T., Niki, H., and Yamazoe, M. 2000. Bidirectional migration of SeqA-bound hemimethylated DNA clusters and pairing of oriC copies in Escherichia coli. Genes Cells 5: 327-341.

Hirano, T. 1999. SMC-mediated chromosome mechanics: A conserved scheme from bacteria to vertebrates? Genes \& Dev. 13: 11-19.

Hirano, M. and Hirano, T. 1998. ATP-dependent aggregation of single-stranded DNA by a bacterial SMC homodimer. EMBO J. 17: 7139-7148.

Holmes, V.F. and Cozzarelli, N.R. 2000. Closing the ring: Links between SMC proteins and chromosome partitioning, condensation, and supercoiling. Proc. Natl. Acad. Sci. 97: 13221324.

Hoshino, T., McKenzie, T., Schmidt, S., Tanaka, T., and Sueoka, N. 1987. Nucleotide sequence of Bacillus subtilis dnaB: A gene essential for DNA replication initiation and membrane attachment. Proc. Natl. Acad. Sci. 84: 653-657.

Hozak, P., Hassan, A.B., Jackson, D.A., and Cook, P.R. 1993. Visualization of replication factories attached to nucleoskeleton. Cell 73: 361-373.

Iismaa, T.P. and Wake, R.G. 1987. The normal replication terminus of the Bacillus subtilis chromosome, terC, is dispensable for vegetative growth and sporulation. J. Mol. Biol. 195: 299-310.

Imai, Y., Ogasawara, N., Ishigo-oka, D., Kadoya, R., Daito, T., and Moriya, S. 2000. Subcellular localization of Dna-initiation proteins of Bacillus subtilis: Evidence that chromosome replication begins at either edge of nucleoids. Mol. Microbiol. 36: 1037-1048.

Ireton, K., Gunther IV, N.W., and Grossman, A.D. 1994. spoOJ is required for normal chromosome segregation as well as the initiation of sporulation in Bacillus subtilis. J. Bacteriol. 176: $5320-5329$

Jensen, R.B. and Shapiro, L. 1999. The Caulobacter crescentus $s m c$ gene is required for cell cycle progression and chromosome segregation. Proc. Natl. Acad. Sci. 96: 10661-10666.

Kato, J., Nishimura, Y., Imamura, R., Niki, H., Hiraga, S., and Suzuki, H. 1990. New topoisomerase essential for chromosome segregation in E. coli. Cell 63: 393-404.

Kelman, Z. and O'Donnell, M. 1995. DNA polymerase III holoenzyme: Structure and function of a chromosomal replicating machine. Annu. Rev. Biochem. 64: 171-200.

Koppes, L.J., Woldringh, C.L., and Nanninga, N. 1999. Escherichia coli contains a DNA replication compartment in the cell center. Biochimie 81: 803-810.

Kornberg, A. and Baker, T.A. 1992. DNA Replication, 2nd ed. W.H. Freeman and Co., San Francisco, CA.

Koshland, D. and Strunnikov, A. 1996. Mitotic chromosome condensation. Annu. Rev. Cell Dev. Biol. 12: 305-333.

Kuempel, P.L., Henson, J.M., Dircks, L., Tecklenburg, M., and Lim, D.F. 1991. dif, a recA-independent recombination site in the terminus region of the chromosome of Escherichia coli. New Biol. 3: 799-811.

Kunst, F., Ogasawara, N., Moszer, I., Albertini, A.M., Alloni, G., Azevedo, V., Bertero, M.G., Bessieres, P., Bolotin, A., Borchert, S., et al. 1997. The complete genome sequence of the gram-positive bacterium Bacillus subtilis. Nature 390: 249-256.

Lemon, K.P. and Grossman, A.D. 1998. Localization of bacterial DNA polymerase: Evidence for a factory model of replication. Science 282: 1516-1519. 
- 2000. Movement of replicating DNA through a stationary replisome. Mol. Cell 6: 1321-1330.

Lemon, K.P., Kurtser, I., and Grossman, A.D. 2001. Effects of replication termination mutants on chromosome partitioning in Bacillus subtilis. Proc. Natl. Acad. Sci. 98: 212-217.

Leonhardt, H., Rahn, H.P., Weinzierl, P., Sporbert, A., Cremer, T., Zink, D., and Cardoso, M.C. 2000. Dynamics of DNA replication factories in living cells. J. Cell. Biol. 149: 271280.

Levin, P.A. and Grossman, A.D. 1998. Cell cycle: The bacterial approach to coordination. Curr. Biol. 8: R28-R31.

Levine, A., Vannier, F., Dehbi, M., Henckes, G., and Seror, S.J. 1991. The stringent response blocks DNA replication outside the ori region in Bacillus subtilis and at the origin in Escherichia coli. J. Mol. Biol. 219: 605-613.

Levine, A., Autret, S., and Seror, S.J. 1995. A checkpoint involving RTP, the replication terminator protein, arrests replication downstream of the origin during the stringent response in Bacillus subtilis. Mol. Microbiol. 15: 287-295.

Lewis, P.J. and Errington, J. 1997. Direct evidence for active segregation of oriC regions of the Bacillus subtilis chromosome and co-localization with the SpoOJ partitioning protein. Mol. Microbiol. 25: 945-954.

Lin, D.C.H. 1999. Chromosome partitioning in Bacillus subtilis. Ph.D thesis, Massachusetts Institute of Technology, Cambridge, MA.

Lin, D.C.H. and Grossman, A.D. 1998. Identification and characterization of a bacterial chromosome partitioning site. Cell 92: 675-685.

Lin, D.C.H., Levin, P.A., and Grossman, A.D. 1997. Bipolar localization of a chromosome partition protein in Bacillus subtilis. Proc. Natl. Acad. Sci. 94: 4721-4726.

Lin, Z. and Mallavia, L.P. 1998. Membrane association of active plasmid partitioning protein A in Escherichia coli. J. Biol. Chem. 273: 11302-11312.

Liu, G., Draper, G.C., and Donachie, W.D. 1998. FtsK is a bifunctional protein involved in cell division and chromosome localization in Escherichia coli. Mol. Microbiol. 29: 893903.

Losick, R. and Shapiro, L. 1999. Changing views on the nature of the bacterial cell: From biochemistry to cytology. I. Bacteriol. 181: 4143-4145.

Löwe, J., Cordell, S.C., and van den Ent, F. 2001. Crystal structure of the SMC head domain: An ABC ATPase with 900 residues antiparallel coiled-coil inserted. J. Mol. Biol. 306: 25-35.

Marston, A.L. and Errington, J. 1999. Dynamic movement of the ParA-like Soj protein of $B$. subtilis and its dual role in nucleoid organization and developmental regulation. Mol. Cell 4: 673-682.

Mehta, A.D., Rief, M., Spudich, J.A., Smith, D.A., and Simmons, R.M. 1999. Single-molecule biomechanics with optical methods. Science 283: 1689-1695.

Melby, T.E., Ciampaglio, C.N., Briscoe, G., and Erickson, H.P. 1998. The symmetrical structure of structural maintenance of chromosomes (SMC) and MukB proteins: Long, antiparallel coiled coils, folded at a flexible hinge. J. Cell Biol. 142: 1595-1604.

Mohl, D.A. and Gober, J.W. 1997. Cell cycle-dependent polar localization of chromosome partitioning proteins in Caulobacter crescentus. Cell 88: 675-684.

Møller-Jensen, J., Jensen, R.B., and Gerdes, K. 2000. Plasmid and chromosome segregation in prokaryotes. Trends Microbiol. 8: $313-320$.

Moriya, S., Tsujikawa, E., Hassan, A.K., Asai, K., Kodama, T., and Ogasawara, N. 1998. A Bacillus subtilis gene-encoding protein homologous to eukaryotic SMC motor protein is necessary for chromosome partition. Mol. Microbiol. 29: $179-187$.

Newport, J. and Yan, H. 1996. Organization of DNA into foci during replication. Curr. Opin. Cell Biol. 8: 365-368.

Niki, H. and Hiraga, S. 1997. Subcellular distribution of actively partitioning $\mathrm{F}$ plasmid during the cell division cycle in $E$. coli. Cell 90: 951-957.

. 1998. Polar localization of the replication origin and terminus in Escherichia coli nucleoids during chromosome partitioning. Genes \& Dev. 12: 1036-1045.

Niki, H., Jaffe, A., Imamura, R., Ogura, T., and Hiraga, S. 1991. The new gene mukB codes for a $177 \mathrm{kd}$ protein with coiledcoil domains involved in chromosome partitioning of $E$. coli. EMBO I. 10: 183-193.

Niki, H., Imamura, R., Kitaoka, M., Yamanaka, K., Ogura, T., and Hiraga, S. 1992. E.coli MukB protein involved in chromosome partition forms a homodimer with a rod-and-hinge structure having DNA binding and ATP/GTP binding activities. EMBO J. 11: 5101-5109.

Niki, H., Yamaichi, Y., and Hiraga, S. 2000. Dynamic organization of chromosomal DNA in Escherichia coli. Genes \& Dev. 14: 212-223.

Ogura, T. and Hiraga, S. 1983. Partition mechanism of F plasmid: Two plasmid gene-encoded products and a cis-acting region are involved in partition. Cell 32: 351-360.

Onogi, T., Niki, H., Yamazoe, M., and Hiraga, S. 1999. The assembly and migration of SeqA-Gfp fusion in living cells of Escherichia coli. Mol. Microbiol. 31: 1775-1782.

Peng, H. and Marians, K.J. 1993. Decatenation activity of topoisomerase IV during oriC and pBR322 DNA replication in vitro. Proc. Natl. Acad. Sci. 90: 8571-8575.

Perals, K., Capiaux, H., Vincourt, J.B., Louarn, J.M., Sherratt, D.J., and Cornet, F. 2001. Interplay between recombination, cell division and chromosome structure during chromosome dimer resolution in Escherichia coli. Mol. Microbiol. 39: 904-913.

Piggot, P.J. and Coote, J.G. 1976. Genetic aspects of bacterial endospore formation. Bacteriol. Rev. 40: 908-962.

Pogliano, K., Harry, E., and Losick, R. 1995. Visualization of the subcellular location of sporulation proteins in Bacillus subtilis using immunofluorescence microscopy. Mol. Microbiol. 18: 459-470.

Pogliano, J., Ho, T.Q., Zhong, Z., and Helinski, D.R. 2001. Multicopy plasmids are clustered and localized in Escherichia coli. Proc. Nat1. Acad. Sci. 98: 4486-4491.

Quisel, J.D. and Grossman, A.D. 2000. Control of sporulation gene expression in Bacillus subtilis by the chromosome partitioning proteins Soj (ParA) and SpoOJ (ParB). I. Bacteriol. 182: 3446-3451.

Quisel, J.D., Lin, D.C.-H., and Grossman, A.D. 1999. Control of development by altered localization of a transcription factor in B. subtilis. Mol. Cell 4: 665-672.

Recchia, G.D., Aroyo, M., Wolf, D., Blakely, G., and Sherratt, D.J. 1999. FtsK-dependent and -independent pathways of Xer site-specific recombination. EMBO J. 18: 5724-5734.

Robinett, C.C., Straight, A., Li, G., Willhelm, C., Sudlow, G., Murray, A., and Belmont, A.S. 1996. In vivo localization of DNA sequences and visualization of large-scale chromatin organization using lac operator/repressor recognition. J. Cell. Biol. 135: 1685-1700.

Sawitzke, J.A. and Austin, S. 2000. Suppression of chromosome segregation defects of Escherichia coli muk mutants by mutations in topoisomerase I. Proc. Natl. Acad. Sci. 97: 16711676.

2001. An analysis of the factory model for chromosome 
replication and segregation in bacteria. Mol. Microbiol. 40: 786-794.

Sciochetti, S.A., Piggot, P.J., Sherratt, D.J., and Blakely, G. 1999. The ripX locus of Bacillus subtilis encodes a site-specific recombinase involved in proper chromosome partitioning. $J$. Bacteriol. 181: 6053-6062.

Sciochetti, S.A., Piggot, P.J., and Blakely, G. 2001. Identification and characterization of the dif site from Bacillus subtilis. J. Bacteriol. 83: 1058-1068.

Sharpe, M.E. and Errington, J. 1995. Postseptational chromosome partitioning in bacteria. Proc. Natl. Acad. Sci. 92: 8630-8634.

-1998. A fixed distance for separation of newly replicated copies of oriC in Bacillus subtilis: Implications for co-ordination of chromosome segregation and cell division. Mol. Microbiol. 28: 981-990.

Slater, S., Wold, S., Lu, M., Boye, E., Skarstad, K., and Kleckner, N. 1995. E. coli SeqA protein binds oriC in two different methyl-modulated reactions appropriate to its roles in DNA replication initiation and origin sequestration. Cell 82: 927936.

Steiner, W., Liu, G., Donachie, W.D., and Kuempel, P. 1999. The cytoplasmic domain of FtsK protein is required for resolution of chromosome dimers. Mol. Microbiol. 31: 579-583.

Straight, A.F., Belmont, A.S, Robinett, C.C., and Murray, A.W. 1996. GFP tagging of budding yeast chromosomes reveals that protein-protein interactions can mediate sister chromatid cohesion. Curr. Biol. 6: 1599-1608.

Sueoka, N. 1998. Cell membrane and chromosome replication in Bacillus subtilis. Prog. Nucleic Acid Res. Mol. Biol. 59: 35-53.

Teleman, A.A., Graumann, P.L., Lin, D.C.H., Grossman, A.D., and Losick, R. 1998. Chromosome arrangement within a bacterium. Curr. Biol. 8: 1102-1109.

Trun, N.J. and Marko, J.F. 1998. Architecture of a bacterial chromosome. ASM News 64: 276-283.

Ullsperger, C. and Cozzarelli, N.R. 1996. Contrasting enzymatic activities of topoisomerase IV and DNA gyrase from Escherichia coli. J. Biol. Chem. 271: 31549-31555.

Vale, R.D. and Milligan, R.A. 2000. The way things move: Looking under the hood of molecular motor proteins. Science 288: 88-95.

van den Ent, F., Lockhart, A., Kendrick-Jones, J., and Lowe, J. 1999. Crystal structure of the N-terminal domain of MukB: A protein involved in chromosome partitioning. Struct. Fold. Des. 7: 1181-1187.

Wang, L. and Lutkenhaus, J. 1998. FtsK is an essential cell division protein that is localized to the septum and induced as part of the SOS response. Mol. Microbiol. 29: 731-740.

Wang, M.D., Schnitzer, M.J., Yin, H., Landick, R., Gelles, J., and Block, S.M. 1998. Force and velocity measured for single molecules of RNA polymerase. Science 282: 902-907.

Webb, C.D., Decatur, A., Teleman, A., and Losick, R. 1995. Use of green fluorescent protein for visualization of cell-specific gene expression and subcellular protein localization during sporulation in Bacillus subtilis. J. Bacteriol. 177: 5906-5911.

Webb, C.D., Teleman, A., Gordon, S., Straight, A., Belmont, A., Lin, D.C.H., Grossman, A.D., Wright, A., and Losick, R. 1997. Bipolar localization of the replication origin regions of chromosomes in vegetative and sporulating cells of $B$. subtilis. Cell 88: 667-674.

Webb, C.D., Graumann, P.L., Kahana, J.A., Teleman, A.A., Silver, P.A., and Losick, R. 1998. Use of time-lapse microscopy to visualize rapid movement of the replication origin region of the chromosome during the cell cycle in Bacillus subtilis. Mol. Microbiol. 28: 883-892.
Weitao, T., Nordstrom, K., and Dasgupta, S. 1999. Mutual suppression of $m u k B$ and $s e q A$ phenotypes might arise from their opposing influences on the Escherichia coli nucleoid structure. Mol. Microbiol. 34: 157-168.

Wendrich, T.M. and Marahiel, M.A. 1997. Cloning and characterization of a relA/spoT homologue from Bacillus subtilis. Mol. Microbiol. 26: 65-79.

Winston, S. and Sueoka, N. 1980. DNA-membrane association is necessary for initiation of chromosomal and plasmid replication in Bacillus subtilis. Proc. Nat1. Acad. Sci. 77: 28342838.

Wu, L.J. and Errington, J. 1994. Bacillus subtilis SpoIIIE protein required for DNA segregation during asymmetric cell division. Science 264: 572-575.

. 1997. Septal localization of the SpoIIIE chromosome partitioning protein in Bacillus subtilis. EMBO J. 16: 21612169.

Wu, L.J., Lewis, P.J., Allmansberger, R., Hauser, P.M., and Errington, J. 1995. A conjugation-like mechanism for prespore chromosome partitioning during sporulation in Bacillus subtilis. Genes \& Dev. 9: 1316-1326.

Yamaichi, Y. and Niki, H. 2000. Active segregation by the $B a-$ cillus subtilis partitioning system in Escherichia coli. Proc. Nat1. Acad. Sci. 97: 14656-14661.

Yamanaka, K., Ogura, T., Niki, H., and Hiraga, S. 1996. Identification of two new genes, mukE and $m u k F$, involved in chromosome partitioning in Escherichia coli. Mol. Gen. Genet. 250: 241-251.

Yamazoe, M., Onogi, T., Sunako, Y., Niki, H., Yamanaka, K., Ichimura, T., and Hiraga, S. 1999. Complex formation of MukB, MukE and MukF proteins involved in chromosome partitioning in Escherichia coli. EMBO J. 18: 5873-5884.

Yoshikawa, H. and Wake, R.G. 1993. Initiation and termination of chromosome replication. In Bacillus subtilis and other gram-positive bacteria: Biochemistry, physiology, and molecular genetics (ed. A.L. Sonenshein et al.), pp. 507-528. American Society for Microbiology, Washington, D.C.

Yu, X.C., Weihe, E.K., and Margolin, W. 1998. Role of the C terminus of FtsK in Escherichia coli chromosome segregation. J. Bacteriol. 180: 6424-6428. 


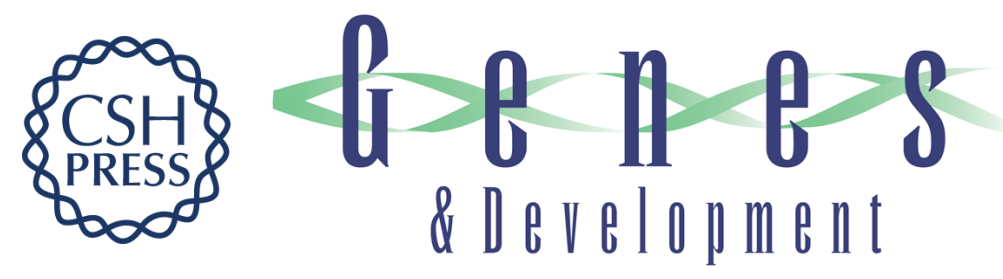

\section{The extrusion-capture model for chromosome partitioning in bacteria}

Katherine P. Lemon and Alan D. Grossman

Genes Dev. 2001, 15:

Access the most recent version at doi:10.1101/gad.913301

References This article cites 114 articles, 47 of which can be accessed free at: http://genesdev.cshlp.org/content/15/16/2031.full.html\#ref-list-1

License

Email Alerting Receive free email alerts when new articles cite this article - sign up in the box at the top Service right corner of the article or click here.

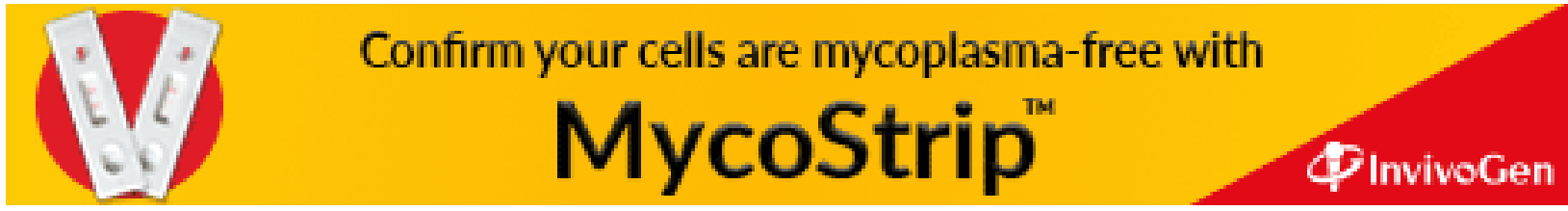

